\section{TEORIAS FRANCESAS DO SÉCULO XVII: NÚMEROS E PAIXÕES - PENSAMENTOS DE PLATÃO, MERSENNE E DESCARTES}

\author{
Rodrigo Lopes*
}

RESUMO: A França do século XVII e da primeira metade do século XVIII é marcada por traços comuns que correspondem não só a ideias artísticas ou técnicas; a música está integrada num todo social e cultural, envolvida com a mentalidade e ideias correntes, não possuindo independência nos diversos domínios onde está inserida. Nesses domínios, a música é também parte integrante de um mundo cósmico e universal como um todo, subjugada ao absolutismo monárquico e ao serviço de Deus. Na hierarquia social, o monarca está em seu ápice, e servi-lo é a maior honra e prestígio que se poderia ter. A compreensão do texto literário é um traço marcante neste período, e a música deve estar a serviço da palavra e da representação das paixões da alma. Essa representação está inserida numa certa teoria das paixões, sua origem é encontrada na concepção platônica da alma e do mundo; como Platão, muitos teóricos do século XVII acreditam que as proporções equilibram as diversas partes de nossa alma, sendo semelhantes às mesmas proporções que fundamentam o sistema musical. Assim, neste trabalho, procura-se observar alguns traços quanto à retórica das paixões e a especulação numérica a partir da análise de aspectos do Timeu de Platão, obra que unifica a doutrina pitagórica dos números e lhe dá um significado cosmológico, pela explicação das proporções matemáticas, onde o microcosmo humano é reflexo das leis do macrocosmo. Além disso, observar aspectos do pensamento de Mersenne que, tributário do pensamento de Platão e Zarlino, possui em sua escritura analogias com uma ordem universal, além de outras analogias místicas e religiosas como argumentos para validar suas ideias musicais como, por exemplo, a adoção da harmonia entre as consonâncias, como o é descrito em sua Harmonie Universelle. Por fim, observar aspectos da nova concepção de ciência do pensamento de Descartes que,
*Instituto de Artes da UNESP

lopes_monteverdi@yahoo. com.br

Auxílio CAPES (Mestrado) 
diferente dos outros, aborda a música por si mesma, como o é demonstrado em seu Compendium Musicae; nele, além de uma rede de analogias e símbolos de acordo com as propriedades do som, são avaliadas a recepção e a percepção do ouvinte perante os fenômenos sonoros. Pretende-se observar como o racionalismo cartesiano suplantou os outros pensamentos e como ele se estabeleceu, fortificando-se como um marco na estética musical.

PALAVRAS-CHAVE: antiguidade, números, música francesa, século XVII.

FRENCH THEORIES OF THE SEVENTEENTH-CENTURY: numbers and passions - thoughts of Plato, Descartes and Mersenne

ABSTRACT: The France of seventeenth-century and the first half of the eighteenth-century is marked by common traits that match not only the artistic or technical ideas, music is integrated in a social and cultural whole, involved with the mindset and current ideas, lacking independence in many areas where it operates. In these areas, music is also an integral part of a cosmic and universal world as a whole, subdued the monarchical absolutism and the service of God. The social hierarchy, the monarch is at its apex, and serve it is the greatest honor and prestige that could have. The understanding of the literary text is a striking feature in this period, and the music must serve the word and the representation of the passions of the soul. This representation is embedded in a certain theory of the passions, its origin is found in the Platonic conception of the soul and the world, as Plato, many seventeenth-century theorists believe that the proportions balance the various parts of our soul, with similar proportions to the same underlying musical system. In this work, we try to observe some features about the rhetoric of the passions and speculation from the numerical analysis aspects of Plato's Timaeus, a work that unifies the Pythagorean doctrine of numbers and gives you a cosmological significance for the explanation of the mathematical proportions where the human microcosm reflects the macrocosm of the laws. Furthermore, to observe aspects of the thought of Mersenne that tax of Plato's thought and Zar- 
lino, in his own analogies with a universal order scripture, and other mystical and religious analogies as arguments to validate their musical ideas, for example, the adoption harmony between consonances, as described in his Harmonie Universelle. Finally, observe aspects of the new conception of science Descartes thought that unlike the other addresses the music itself, as is demonstrated in his Compendium Musicae; him, plus a network of analogies and symbols according to sound properties are evaluated reception and perception of the listener before the sound phenomena. Want to be seen as Cartesian Rationalism supplanted other thoughts and how he settled, fortifying it as a milestone in musical aesthetics.

KEYWORDS: antique, numbers, French music, seventeenth-century.

\section{INTRODUÇÃO}

No século XVII uma unidade social comum orienta o caráter, o comportamento, a mentalidade, as ideias, e guarda uma série de características comuns, e neste contexto a música se insere subserviente aos domínios da cultura e da vida social.

Desde o século XVI a epistemologia já se caracterizava pelo discurso analógico simbólico, fundamentado através de um princípio de harmonia geral do cosmos onde cada uma de suas partes possui relação umas com as outras na formação de uma totalidade.

$\mathrm{Na}$ música tem-se a polaridade melodia-harmonia, como oposições, em contrastes. As conotações na música são mais ou menos precisas, encerrando significações filosóficas e cosmológicas cujo múltiplo está em acordo na unidade, como ocorre com os planetas.

Época da representação das paixões, o aspecto textual na música vocal é de grande importância, pois o texto deve ser claramente compreendido; o sentido das palavras, dentro dos estilos representativo e recitativo, deveria ser o conteúdo musical e extra musical principais, próximo do gesto da palavra falada e possuidora da eloquência do orador. $\mathrm{O}$ texto literário, a inteligibilidade da palavra, são as metas desse tipo de música que se configura como a um discurso. 
Esse período valorizou fortemente a exegese e interpretação de textos, e foi conduzido pela importância do texto. Esses dois elementos organizavam o jogo de símbolos, o que para a sociedade dessa época permitia o conhecimento das coisas visíveis e invisíveis. Era isso que guiava a arte da representação.

As diversas paixões, sentimentos e emoções foram organizados em códigos, comunicando sentimentos determinados, de maneira simbólica. Neste saber a música possui em essência o papel de espelhar o universo, de materializar o macrocosmo e responder pelas relações que o estruturam.

Por existir uma percepção do papel da música na sociedade, filósofos e teóricos da música no século XVII se ocuparam com uma teoria das paixôes e uma mística dos números. É uma teoria da harmonia que se remete à antiguidade, que se remonta em sua origem na filosofia pitagórica, e persiste até o século XVII. Um pensamento analógico de tradição platônica ainda serve de base para um modelo epistemológico na música e nas ciências, destacando-se dele um impulso cartesiano e uma nova concepção de ciência.

\section{Timeu de Platão}

A coesão do Cosmos, compreendida como uma ordenação do caos, é descrita no Timeu como regulada através de proporções matemáticas. Essas proporções são as mesmas usadas no sistema musical grego. Nele a doutrina pitagórica dos números é retomada através de um significado cosmológico, e aborda o processo de criação do mundo e de todas as coisas que vivem nesse mundo. A cosmologia tenta explicar o mundo através de axiomas e pressupostos consistentes, embora a mudança constante do mundo traga problemas para a constituição de um objeto de verdadeiro saber. Platão então se fia no discurso verossimilhante, trazendo uma proposta de explicação plausível ao invés do uso da certeza. O que acabou gerando uma narrativa especulativa em seu ponto de partida.

O universo platônico é regulado por relações matemáticas, e são essas relações que justificam seu estado quanto a ser belo e bom. Como a alma humana é formada também por proporçôes matemáticas, o universo deve ser o seu exemplo. A alma humana é um microcosmo, uma redução do universo que, como macrocosmo, assegura unidade e coesão. É possível 
então fazer uma analogia entre o micro e macro; por ser uma redução do macro quanto à essência do universo e de suas leis, a alma humana examinada permite compreender a complexidade desse universo. Há uma estrutura comum, segundo Platão, que permite estabelecer uma unidade entre os dois.

$\mathrm{E}$ os movimentos que têm afinidade com o princípio divino em nós, são os pensamentos do Todo e suas revoluçôes circulares. Eles são os únicos que todos devem seguir: as revoluçôes relativas quanto ao destino, que tem lugar na nossa cabeça e que nos perturbam, devem recuperar o conhecimento da harmonia e a revolução do Todo: que este que contempla se faça semelhante ao objeto de sua contemplação (...) e que ele se estenda para o presente e para o futuro, para a conclusão perfeita da vida que os deuses propuseram aos homens (PLATON, 1985, p. 226).

Observa-se então o estabelecimento do mundo sensível, focado no homem, eixo da narrativa do Timeu. Havia uma abordagem naturalista advinda dos pré-socráticos, e o Timeu então seria uma proposta de substituição desse pensamento. Sua cosmologia é tratada no sentido de como seu equilíbrio é garantido; o demiurgo fabrica a alma do mundo; invoca deuses antes de iniciar seu discurso. $\mathrm{O}$ objetivo do diálogo é mostrar aos homens o conhecimento do processo de constituição do mundo, revelar aquilo que está na esfera do mundo divino. Através do pitagorismo Platão terá condições de sondar aspectos divinos para a compreensão do mundo e do homem e, assim, chegar aos poucos à sua criação.

Essas ferramentas são, fundamentalmente, a matemática - sobretudo as suas vertentes geométrica e estereométrica -, a música e a astronomia que, utilizadas em conjunto, permitirão uma observação do mundo fenomênico de que se poderão retirar conclusões com valor filosófico (LOPES, 2011, p. 29).

A alma do mundo e dos homens segue uma partição comum, dividida em proporçôes iguais, e, desta forma, a música segue essa partição através das leis do universo, já que ela é estruturada também através de proporções matemáticas. As relações matemáticas regulam as afinidades dos sons, e compreendendo-as, compreende-se a harmonia do universo. 
(...) é através da harmonia proporcionada pela música que se pode conceber a dos movimentos dos corpos celestes, na medida em que ambas obedecem a um mesmo princípio cinético: na segunda [órbita pôs] o Sol, por cima da Terra; a Estrela da Manhã e o astro que dizem ser consagrado a Hermes na rota circular que tem a mesma velocidade que o Sol, ainda que lhes tenha cabido em sorte um ímpeto contrário ao dele. Daí decorre que o Sol e a Estrela da Manhã (o astro de Hermes) sucessivamente se alcancem e sejam alcançados mutuamente. (38d1-6).

De facto, os sons mais lentos apanham os movimentos que de entre os mais rápidos chegaram primeiro e, quando esses movimentos estão a cessar e atingem a constância, chocam com os últimos e põem-nos em movimento. (80a6-80b1) (LOPES, 2011, p. 30).

Platão então recomenda a música como um aprendizado para compreender o princípio de coesão do mundo. Não se prende aos prazeres dos sentidos que a música pode proporcionar, mas seu aprendizado permite elevar o espírito aos Números e aos ideais que estruturam o cosmos. A música é uma aliada da alma humana porque se movimenta como esta, apesar de não existir uma ligação perfeita devido à sua união com o corpo mortal.

Os astros, tal como os sons, circulam juntos a diferentes distâncias uns dos outros - os astros em espaço, os sons em tempo, mas de acordo com uma mesma relação numérica que determina a harmonia do conjunto; é a este raciocínio que, segundo Aristóteles (Sobre o Céu, 291a10-11), os Pitagóricos chamavam "a música das esferas", cuja adaptação é evidente no sistema que propõe o Timeu. Neste diálogo, Platão parece recuperar a identificação que Sócrates faz na República (531a-c) entre música e astronomia. Ao distinguir os músicos que se dedicam à demanda do intervalo mínimo mensurável, condenáveis por se aterem em demasia à percepção sensível do som, daqueles que procuram os números nos acordes que escutam, diz que são estes últimos que se aparentam aos que estudam os astros. Esta teoria da música que Sócrates elogia é a pitagórica (LOPES, 2011, p. 30-31).

"Assim, os três intervalos da progressão de duplos e triplos, os medianos de um mais um meio, um terço, um oitavo e as 
ligações que resultam (...) até serem torcidas e deformadas em todos os sentidos" (PLATON, 1985, p. 159-160).

Estando em acordo com a alma do mundo, a alma humana realiza um equilíbrio, e a música é o exemplo dessa harmonia entre as duas almas. Para realizar o equilíbrio em si mesmo, o homem deve encontrar respaldo e justificativa na teoria do éthos modal.

Os modos possuem efeitos sobre a alma humana, e eles devem ser usados, segundo como desenvolve Platão, para se chegar a significados próximos da política e da ética, como descrito na República e nas Leis.

Através do Timeu, a filosofia musical foi influenciada, estabelecendo uma visão musical do mundo, cujos elementos são relacionados uns com os outros em harmonia. A música então reflete estruturas macro e microcósmicas, reflete a estrutura matemática do cosmos, além de ser o espelho da alma humana e de suas emoções. Buscando o que é necessário saber sobre este universo, é possível estabelecer normas estilísticas para composições musicais.

O compositor é, portanto, um ser comparável ao demiurgo. É um organizador. A partir de um substrato sonoro, ele estrutura e harmoniza o universo musical, com os olhos fixos em seu modelo. E que este produto da sorte é necessariamente belo: todas às vezes em que o trabalhador estiver com os olhos constantemente fixos no que é o idêntico, ele usa um modelo, todas às vezes que ele se esforça para realizar seu trabalho com a mesma forma e propriedades, tudo o que ele produzir desta forma é necessariamente belo (PLATON, 1985, p. 140).

\section{A FranÇA DO SÉCULO XVII}

Muitas referências foram feitas a Platão no século XVII. Tentava-se, assim, conciliar nesse período, a tradição pitagórico-platônica com os avanços e reflexóes musicais. Por exemplo, Zarlino, que concebe uma mística do número onde tem na música um espelho da harmonia do cosmos.

A Natureza é concebida como numericamente ordenada, harmoniosa e boa, e ela é o exemplo superior que todo homem deve seguir. A natureza segue as leis do universo, e, imitando-as, a base e a beleza da obra de arte são garantidas. A natureza guarda em si leis numéricas e, na música, as consonâncias são 
baseadas em especulação numérica, através dos intervalos, que são os números harmônicos, os mesmos números fundadores do universo. E por este motivo são chamados de consonantes, já que estão próximos da ordem natural, e por isso mesmo seu uso deve ser feito nas composições musicais.

Esses intervalos espelham a ordem natural do universo, e por isso os compositores devem usá-los.

Esta visão harmoniosa do universo se encontra como tal em numerosas teorias. Ela já foi um lugar comum da literatura do Renascimento, mas sua aquisição por Zarlino como um elemento fundador do sistema de música e técnicas da escritura contemporânea explica a influência considerável deste modelo de pensamento sobre os teóricos do século XVII (BROSSARD, 1703, p. 19).

Sendo tudo música, mesmo em tratados técnicos da época, o universo possui elementos que em sua composição se inclui o homem, em equilíbrio:

A música (falando em geral) não é outra coisa senão Harmonia; onde é um acorde de coisas diversas que podem ser unidas. Existem três tipos de música, a saber: a Mundana, a Humana \& Instrumental. A primeira considera os diversos movimentos e partes do céu, com todas as relações harmônicas que lá se encontram. A segunda contempla a proporção das partes e humores do corpo humano, e as harmonias da Alma, tanto a razão de suas faculdades, paixões e ações como de suas virtudes. E esta palavra de música é mais frequentemente tomada por uma proporção, simetria, concórdia e amizade dos corpos celestes, e da Natureza Universal, tanto no universo em geral, como especialmente de um corpo particular para outro particular, e por isso ele nomeia de Música Mundana \& Humana. A terceira trata dos instrumentos naturais e artificiais, de tudo o que lhe pertence, e geralmente de tudo que diz respeito ao canto; é esta terceira Música Instrumental - que quero tratar agora, deixando de lado os dois primeiros que são a Mundana e a Humana que eu estimo ser mais curioso do que o necessário (COUSU, 1658, p. 1-2).

Muitos autores do século XVII se dedicaram a uma escrita com perspectiva analógica, tratando a música como ocupada 
de números e medidas, cuja simetria já tinha sido reconhecida pelos antigos, tanto nos sons quanto nas vozes.

A maioria desses teóricos acreditava que as proporções que fundamentavam o sistema musical eram as mesmas que equilibravam as partes de nossa alma. Essa analogia pensa como sendo a música capaz de fazer vibrar nossa alma, comovendo-a.

Pela teoria das paixóes - já evidente na época - e dos modos, as diversas paixões e afetos da alma possuem relação com as qualidades dos modos, assemelhando-se em proporções.

Nesse período as paixões possuem relações com a linguagem musical, e o compositor deve buscar em suas composições a força expressiva necessária para facilitar o significado do texto, da palavra.

Em comparação com a antiguidade, havia discussões sobre os efeitos da música antiga comparada com a moderna. Já Mersenne afirmava que os filósofos e teóricos gregos faziam correspondências entre a música e as paixões; ele dizia que "os gregos tinham conhecimento do temperamento dos ouvintes, da natureza das paixões e dos intervalos" (MERSENNE, 1636, p. 98).

As regras para se compor estavam baseadas na compreensão da letra, do texto. O texto, atrelado ao modo, produziria um efeito específico nos ouvintes, e por isso os modos eram classificados, pois neles estavam contidos as causas, o gosto, a força e os sentimentos da música.

Para compreendê-los, procurava-se recuperar os antigos modos, em comparação com os existentes da igreja: cada um deles possui uma paixão específica. $\mathrm{O}$ dórico, por exemplo, era considerado um modo grave, próprio para o canto piedoso, sendo severo, mesclando alegria; o segundo exprime sentimentos amorosos devido à sua afinidade com o intervalo de sexta. Essa tipologia existente permitia ao compositor usar o modo mais apropriado ao tema por ele escolhido em suas composições.

O tema e o modo eram escolhidos com cuidado, para que o sentimento de alegria, por exemplo, não fosse confundido com um estado lúgubre. A importância desse cuidado era devido ao caráter ético do modo, comum na literatura francesa, voltado ao aspecto moral. A teoria dos modos tinha a função de moralizar, e não era apenas uma teoria. 
Progressivamente na França essa tipologia dos modos foi desaparecendo devido ao crescimento da importância da bipolaridade modal sobre a posição da terça maior da escala musical, já que o temperamento igual foi aos poucos sendo adotado.

Além dos modos, os ritmos poéticos foram bastante usados, e neles o que comove a alma é a combinação de ritmos longos e breves, pois o que afeta o espírito é o argumento do texto, seu significado, e é nele onde a música se apoia.

\section{Harmonie Universelle: Padre Mersenne}

Baseado em modelos analógicos, Marin Mersenne guarda em seus escritos analogias com a ordem universal, como as teorias zarlinianas. Mersenne na Harmonie Universelle alcançou resultados no campo da música, da acústica e da técnica de construção de instrumentos musicais.

Subsistem em sua obra aspectos puramente retóricos, além de elementos comuns em muitos outros escritos de sua época, como a tipologia dos modos e a importância rítmica. Para ele, a música não deve se inspirar somente no texto, mas também nos princípios da retórica clássica, fazendo aquele ser portador de emoção e sentido.

Mersenne adota os princípios da nova racionalidade, mas está impregnado do paradigma analógico, como vemos em sua Harmonie Universelle. Mersenne segue uma ordem místico-religiosa para validar suas ideias musicais. Ele parte da adoção do uníssono advindo das consonâncias. Ele assegura o uníssono como a imagem de Deus, e por isso ele é o mais perfeito som consonante, por refletir a elevação do espírito a Deus. Assim, ele se expressa:

É fácil se obter grande proveito espiritual de tal discurso [sobre o uníssono], pois que os Músicos não sentirão necessidade de novas instruçôes para se dirigirem a Deus, pois que o uníssono de todas as coisas do mundo os conduz; porque tudo o que se produz na terra se faz pelo uníssono dos raios do sol, e os outros astros que se unem com cada planta, quando eles despertam a natureza e quando os faz crescer: e quando os membros obedecem à alma, é para este movimento dos espíritos que estão se movendo, como o uníssono faz mover os acordes (...). Se considerarmos o conhecimento da verdade, admitimos que esta não é outra coisa senão 
que o uníssimo que ela se faz com o entendimento; e se ainda se eleva mais alto, vemos que é pela força do uníssono que Deus faz agir sobre todas as criaturas, e que ele nos converte a ele pela graça eficaz que é semelhante a um acorde, cujos batimentos são tão possantes que eles sempre agitam nossa vontade sem que ela jamais seja resistente (MERSENNE, 1636, p. 22).

Embora Mersenne explique os movimentos das cordas na produção do uníssono pela demonstração de um esquema físico das cordas em vibração, de forma científica e racional, ele adequa seu discurso ao serviço de Deus e de sua representação. Seu pensamento analógico está voltado para o criador, através de metáforas, comparações e pelo uso de citações filosóficas em meio às citaçôes das sagradas escrituras; ele se volta mais para a moralidade do que para os efeitos musicais. E por esse viés, seu pensamento analógico possui maior eficácia do que o pensamento racional.

Podemos dizer que toda música não é quase outra coisa senão o Uníssono, como as virtudes não são outra coisa que o amor, e, consequentemente que o amor e o uníssono são semelhantes. Para as consonâncias são qualquer coisa de bom agradável; elas levam o uníssono, como todas as virtudes têm sua bondade e sua excelência do amor. O que pode ser confirmado pela autoridade de Santo Agostinho (MERSENNE, 1636, p. 30).

\section{Compendium Musicae: Descartes}

Descartes trilhará outro tipo de pensamento, diferente de Mersenne. Ele considera a música por si mesma, rompendo com o pensamento epistemológico. Sua noção musical não é mais a que representa a ordem do cosmos, o que marca uma transformação na estética musical.

Ele fundamenta uma autonomia do discurso musical, cuja filosofia e teoria da música não dependem mais da cosmologia e teologia. Descartes pensa em regras musicais, como por exemplo, o número de consonâncias admitidas na composição, os movimentos das vozes, e não mais as justifica através dos símbolos e analogias, porém visa focar as funções das propriedades sonoras em si mesmas, pensando nos efeitos musicais recebidos pelos ouvintes. 
Partindo para uma estética mais subjetiva, Descartes acredita que a apreciação do intervalo, na verdade, reforça o domínio do julgamento pessoal, mais do que a perfeição acústica em relação aos números. Ele escreve a Mersenne em 1630 dizendo não reconhecer os pontos característicos das consonâncias correspondentes às paixões. Para ele as paixões são classificadas como percepçôes que se relacionam com a própria alma. Elas são sentimentos porque a alma as recebe da mesma maneira como se recebe objetos externos, e é esse recebimento que movimenta a alma.

As paixões não possuem relação com o corpo, da maneira como sentimos, por exemplo, o frio. Elas não representam objetos, pois são particulares à alma, e só temos somente consciência de seus modos de ser, embora, no entanto, sejam causadas pelo corpo. A origem das paixôes está no corpo físico, daí a alma não ter controle sobre elas. A ação das paixões está em elas serem representadas através de objetos que suscitam paixões. Daí a razão ser a reguladora das paixões, originadas no corpo. A alma pode decidir e conduzir as ações.

Descartes diz que uma mesma causa pode provocar diversas paixões, o que possui mais relação com a história pessoal de cada um do que com determinadas causas exteriores. Os movimentos transmitidos ao cérebro "representam os objetos à alma e fazem-na ter diversas sensações" (ROVIGHI, 2006, p. 109).

Existem, para Descartes, seis paixões distintas, das quais todas as outras dependem delas: são a admiração, amor, ódio, desejo, alegria e tristeza.

Todas as paixões são reações da alma ao que é benéfico ou nocivo (art. 52); mas, na frente de todas essas reaçóes, Descartes põe a admiração, suscitada por aquilo que é novo e inusitado nos objetos (art. 53). É uma paixão que tem por objeto o conhecimento, e por isso seus movimentos permanecem no cérebro (art. 71). A admiração suscita o desejo de conhecer, reforça a atenção, é mãe do saber (art. 75), mas mesmo esta é moderada, porque poderia levar-nos a querer conhecer também o que não vale a pena (ROVIGHI, 2006, p. 111).

No entanto, sua filosofia, se assim se pode dizer, contida no Compendium Musicae, aborda a questão do belo a partir dos problemas musicais e acústicos. A música é um suporte para a reflexão estética, embora se aprofunde em questôes téc- 
nicas e acústicas; seu pensamento conduziu a uma estética de tendência "clássica", mas subjetiva.

Descartes recupera as teorias antigas, muito desenvolvidas nos escritos do século XVI, mas as coloca numa "roupagem" epistemológica nova, fora do discurso metafísico e cosmológico sustentados nesse período. Sua obra possui uma ambiguidade, segundo Wymeersch (WYMEERSCH, 1999, p. 113), pois apresenta uma aparência clássica, e na sua estética das paixões, o prazer das emoções parecem ser superiores à razão; apresenta concepções clássicas do prazer estético, pois para ele todos os sentidos são capazes de qualquer prazer.

Em seu pensamento os objetos são adaptados, estabelecidos em proporções, de modo que se possa apreendê-los pelas sensaçôes, de maneira distinta e sem dificuldades. Nesse sentido, a proporção é aritmética, não geométrica, pois esta seria uma proporção irracional, não perceptível pelos sentidos, e isso fatigaria os sentidos. A beleza depende de uma adaptação do objeto aos sentidos percorridos e da proporção interna de seu objeto, qualidade objetiva apreciada pela razão. $\mathrm{O}$ critério principal para o julgamento da beleza de uma obra é sua justa proporção.

Por isso os ritmos na música devem ser iguais, para que o canto dê uma impressão de unidade. Proporção, equilíbrio, unidade e simetria são as noções características da estética dita "clássica". O belo faz sua ligação com o objeto musical e não com o sujeito que o contempla.

O objeto da música é o som, e o seu fim é o prazer de mover em nós as várias paixões. A essência da música é suscitar no ouvinte uma reação; mais importante que o prazer em si mesmo é o sentimento de prazer que sentimos dentro de nós mesmos. Ele não é unicamente intelectual, mas é ligado à sensação.

O ego tem sua subjetividade exacerbada pela emoção e paixões, mas é pelo reforço da razão que se adquire o conhecimento do universo e o controle das emoçóes.

Descartes não aborda mais o domínio da música cósmica, da harmonia das esferas. A sua música que canta é a música humana - instrumental ou vocal, esta que é feita para e pelos homens. 
Nessas explanações, procurou-se observar brevemente que o século XVII na França possuiu um domínio voltado para uma estética dos números e paixões a partir do princípio da analogia. Esse pensamento aos poucos foi desaparecendo com a aquisição do pensamento racional. $\mathrm{Na}$ medida em que os autores puderam imaginar um universo harmonioso, o pensamento analógico se fez presente nos graus diversos da implicação musical. Tudo nesse pensamento se correspondia. Com Descartes e o inicio da chegada do "grand siècle", uma distância é marcada quanto a esse pensamento, e cada vez mais começa a existir um refutamento da correspondência entre a analogia musical e universo-homem, assim como um distanciamento da ligação música-números-paixões. Algumas tomadas de posição ocorreram, coexistindo teorias de base platônica, como a do padre Mersenne, e outras mudanças de pensamento, como em Descartes.

REFERÊNCIAS BIBLIOGRÁFICAS

BROSSARD. S. Dictionnaire de musique contenant une explication des termes grecs, latins et italiens et français les plus usités dans la Musique. Paris, 1703.

COUSU. A. La musique universelle, contenant toute la pratique et toute la théorie. Paris, 1658.

DESCARTES. R. Lettre à Mersenne du 4 mars 1630. Paris: Ed. Adam et Tannery, tomo I, s/d.

MASSIN, J \& B. História da música ocidental. Rio de Janeiro: Editora Nova Fronteira, 1997.

MERSENNE, M. Harmonie Universelle, Livre premier des consonances, proposition IV, Corollaire IV. Paris, 1637, tomo II.

PlATÃO. Timeu-Crítias. Coimbra: Centro de Estudos Clássicos e Humanísticos da Universidade de Coimbra, 2011. (Tradução do grego, introdução e notas: Rodolfo Lopes, Coleção Autores Gregos e Latinos, Série Textos).

PLATON. Timée. Paris: Les Belles Lettres, 1985. 
ROVIGHI, S. V. História da filosofia moderna: da revolução cientifica a Hegel. São Paulo: Ediçôes Loyola, 2006.

STANLEY, S. Dicionário Grove de Música, edição concisa. Rio de Janeiro: Jorge Zahar Editor, 1994.

WYMEERSCH. B. V. Descartes et l'évolution de l'esthétique musicale. Paris: Mardaga, 1999. 